\title{
Simulation modeling - An effective method in doing business and management research
}

\author{
Nguyen Thi Bich Tram ${ }^{*}$ \\ ${ }^{1}$ Ho Chi Minh City Open University, Vietnam \\ *Corresponding author: tram.ntb@ou.edu.vn
}

\begin{tabular}{|c|c|}
\hline 0 & ABSTRACT \\
\hline $\begin{array}{l}\text { Received: June } 04^{\text {th }}, 2021 \\
\text { Revised: August } 17^{\text {th }}, 2021 \\
\text { Accepted: August } 24^{\text {th }}, 2021\end{array}$ & $\begin{array}{l}\text { Although simulation modeling is a popular method in doing } \\
\text { scientific research for many disciplines, namely decision science, } \\
\text { optimization, information technology. Social science disciplines, } \\
\text { particularly business and management, still receive little attention } \\
\text { in applying this method. The paper introduces simulation modeling } \\
\text { as an effective method in doing business and management research } \\
\text { using Dimensions database and comparative analysis to explore (1) } \\
\text { suitability and contribution in general disciplines as well as } \\
\text { business and management, (2) advantages and disadvantages, (3) } \\
\text { common types of models, and (4) effective software that } \\
\text { researchers could use for specific research problems. The findings } \\
\text { of this study confirm that simulation modeling is an effective } \\
\text { method in doing business and management research thanks to its } \\
\text { abilities in dynamics reflecting the real world, abstracted } \\
\text { illustration, and naturally accommodating more plausible } \\
\text { behavioral assumptions. However, modelers need to be aware of } \\
\text { computational possibilities, the model's complexity, and validity } \\
\text { which might impact the simulated research results. The objective } \\
\text { of this study is a calling for more simulation-based research to } \\
\text { tackle complicated study problems related to business } \\
\text { organizations with advanced technology and powerful tools listed } \\
\text { in the paper. Thus, modelers are served well by this work as a } \\
\text { reference for basic knowledge related to simulation modeling in } \\
\text { business and management research. }\end{array}$ \\
\hline
\end{tabular}

\section{Introduction}

Problems in the real world are usually uncertain, complex, and affected by multiple related factors and interdependent processes. In business and management research, all possibilities are used to capture this complexity of the real world. Many authors argued that traditional approaches to theory development in business and management are restricted in their ability to analyze multiple interdependent processes operating simultaneously (Levinthal \& Marengo, 2016; Maina \& Mwangangi, 2020; Thierry, Bel, \& Thomas, 2010). In particular, empirical analysis has limited value in using the general linear model, especially when samples are sparse in the regions of most significant interest (Harrison, Lin, Carroll, \& Carley, 2007).

Simulation modeling is an effective way to simulate a real system through its 
representation in a modeling language. Although modeling is grounded on decision science and information technology disciplines, this method is considered a more systematic and valuable methodology for theory development and analysis in business and management research (Borshchev, 2013). However, academia in business and management has not taken advantage of simulation methods effectively in doing research. Meanwhile, scientists in other social science disciplines, such as psychology, seem to be far ahead compared to applying simulations by managers to set policy and study organizational problems (Harrison et al., 2007). Extensive research in business and management is dominated by quantitative methods such as correlational, causal, and comparative approaches based on surveys (Creswell \& Creswell, 2018). Considering its quantitative characteristics in applying mathematical models, simulation modeling still receives little attention from researchers in the business and management discipline.

The aim of this article is to provide a literature review on the contribution of simulation modeling to scientific knowledge and the overview of simulation methodology, including pros and cons, popular methods, and up-to-date software based on the current literature and comparative analysis. Thereby, the author seeks to embolden business and management scholars to use simulation methods proficiently, take their fuller advantages and keep in mind some limitations to improve this discipline's research impact in social science. Understanding what simulations are and how they work is a vital component in appreciating the potential contributions of simulation analysis to business and management theories and plays a crucial role in developing simulationbased research.

The paper is constructed as the following. First, the research methodology of this study is briefly represented in the next section. The contributions of simulation research for generating new knowledge have been discussed in general disciplines and only in the field of business and management in Section 3. Section 4 analyzes the advantages and disadvantages of simulation modeling for business and management studies. Then, this study set out to introduce different types of simulation models that can be applied to doing simulation research in Section 5. In the end, the author suggests some helpful and available software that business and management scholars could apply to do research in this area using comparative analysis among available software in Section 6. It is hoped that this research will contribute to a deeper understanding of the features, types of simulation-based work, and a recommendation in selecting suitable software for business and management researchers.

\section{Research methodology}

\subsection{Literature review method}

In this study, to understand the research landscape of simulation modeling solely through the lens of publication and citation data, Dimensions is used to analyze the literature. Dimension is a scientific database applying machine learning and artificial intelligence technologies to use existing classification systems and automatically assign a consistent set of categories to all documents, regardless of the source (Bode, Herzog, Hook, \& Mcgrath, 2019). Existing databases such as Web of Science and Scopus are not used in this study because, in those databases, the documents are typically categorized using a journal as a proxy, with a few research categories being assigned at the journal level. The approach of Dimensions helps to create unintended consequences across research from content coverage in databases to citation benchmarking practices. In addition, Dimensions links and integrates data from multiple sources. Currently, it is the world's largest linked research information dataset with more than 120 million publications, six million grants, nine million datasets, and so on (Hook, Porter, \& Herzog, 2018). Research categories in Dimensions are components of many systems, such as the Australian and New 
Zealand Standard Research Classification (ANZSRC) system.

Even Dimensions is a new tool to link and explore the research databases, it has been used and recommended widely by researchers in multiple disciplines to do literature review namely Adams et al. (2018); Bode et al. (2019); Bresciani, Ciampi, Meli, and Ferraris (2021); Gnanapragasam et al. (2021); Hook et al. (2018); Jiang and Wen (2020). Dimensions provide three features that are used and shown in this research. First, a solid citation graph of the kind offered by Scopus or Web of Science, as seen in Section 3, illustrates the contribution of simulation modeling in the knowledge. Second, Dimensions widely covers and enhances experience around discovering the right or most relevant research based on indexing the full-text, which is similar to the approach of Google Scholar. Finally, it provides a broad, linked, and rich view on content relevant for the research process to avoid the narrow focus on publications and citations. Therefore, it allows a deeper understanding of the inputs, outputs, and impact and how they are related to simulation modeling with a wide range of indicators (Bode et al., 2019).

\subsection{Comparative analysis}

Comparative research is a method that offers the opportunity to address a particular set of questions that are of crucial importance for our understanding of a wide range of processes. The underlying goal of comparative analysis is to search for similarity and variance. Those searching for similarity often apply a more general theory and search for universals or underlying general processes across different contexts (Mills, van de Bunt, \& de Bruijn, 2006). Hence, a comparative analysis could be used to perform many important functions that are closely interlinked. In particular, according to Esser and Vliegenthart (2017), comparative analysis enhances the understanding by placing its familiar structures and routines against those of other systems. It helps to heighten awareness of different systems and patterns of thinking and acting. Also, the comparison provides scholars access to a wide range of alternative options and problem solutions that can facilitate or reveal a way out of similar dilemmas (Hantrais, 2008). Usually, to organize a comparative analysis, the alternating (point-by-point) method is to find similar points between each subject and alternate writing about each of them. In this study, alternating method as comparative analysis is applied to compare the contribution of simulation modeling in general and business and management disciplines. Also, an alternating method is used to find similarities and differences point-by-point among available software to identify which one is the most suitable tool for management researchers based on many criteria, namely cost, number of users, ratings, and so on.

\section{The contribution of simulation research}

\subsection{General disciplines}

There are two methodologies of scientific progress in history, including theoretical analysis or deduction and empirical analysis or induction (Harrison et al., 2007). A set of assumptions is formulated, and the consequences of those assumptions are then deduced in the deductive form of science. Meanwhile, researchers observe variables (data) and then analyze the data to uncover relationships among the variables in the inductive form of science. As a third way of doing science, computer simulation renders irrelevant the deductive problem of analytic intractability, which means mathematical relationships can be handled computationally using numerical methods (Axelrod, 1997). In addition, its own "virtual" data is compelling in overcoming the empirical problem of data availability. On account of these features, computer simulation can support theory construction. Making more realistic assumptions rather than compromising with analytically convenient ones is easier for scientists, which is common in deductive theory (Levinthal \& 
Marengo, 2016). Finally, hypotheses that are integrated and consistent can be generated by a computer simulation.

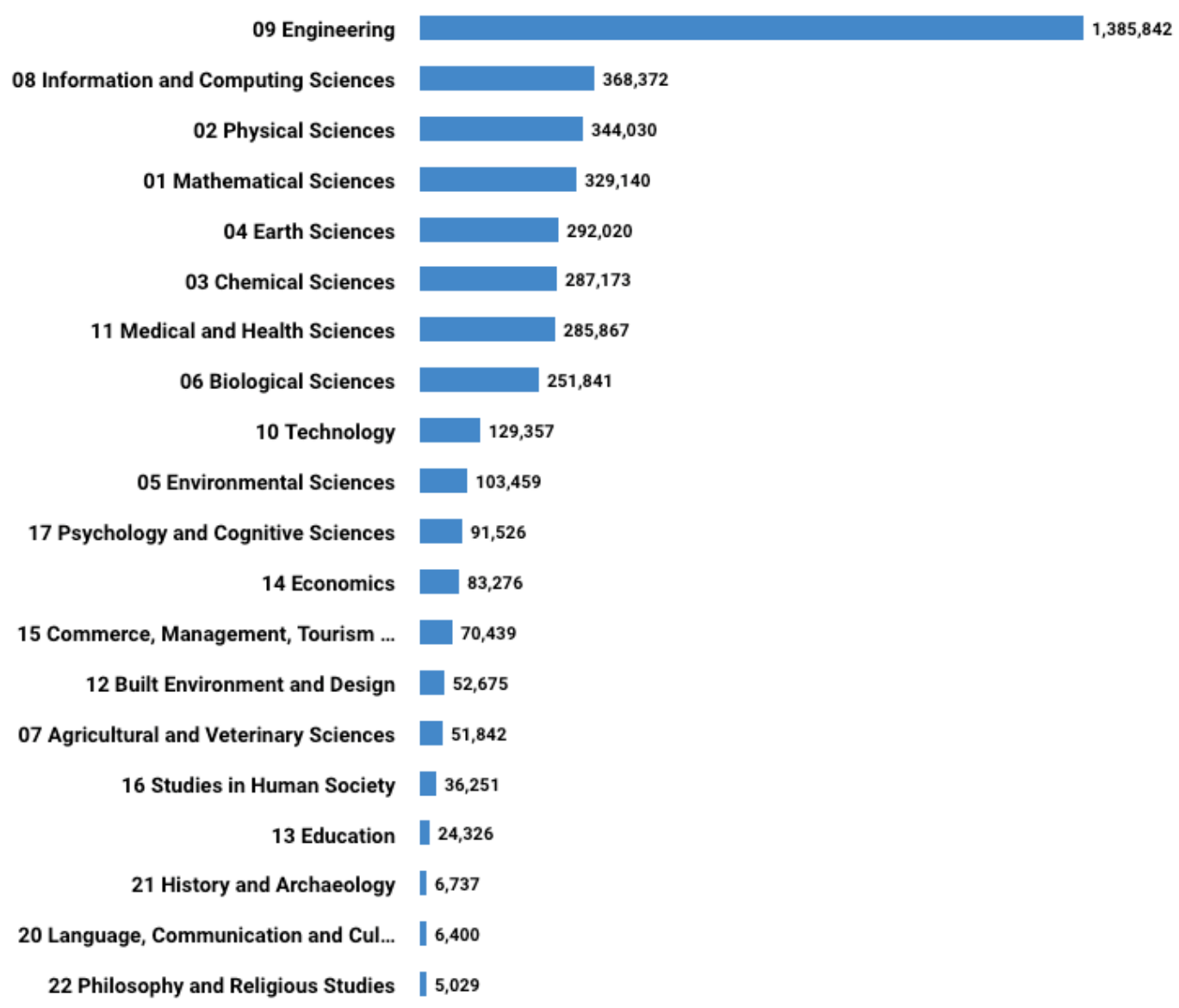

Figure 1. Top 20 disciplines applied simulation modeling

Source: The author's analysis on Dimensions

In other words, computers provide scientists with a flexible virtual world where it is easy to create almost anything researchers can imagine. These features are naturally and extensively used for modeling. According to Levinthal and Marengo (2016), simulation models provide a distinct analytical approach from closed-form mathematical modeling. For example, in agentbased modeling, the agent, or micro-entity, is characterized as well as the nature of the interaction with the environment and other agents. The analysis consists of characterizing the emergent behavior from these interactions. Therefore, simulation modeling studies contribute to knowledge in many fields. To clarify the contribution of simulation research, the literature on simulation modeling is analyzed by Dimensions in this study. Specifically, the author calculates the proportion of simulation-based articles appearing in leading journals across various disciplines from 2001 to 2021 . There is a total of 3,493,312 articles related to those using simulation modeling. The findings are summarized in Figure 1. There are many disciplines of applied simulation modeling, including engineering, medical and health sciences, education, technology, psychology, etc. 


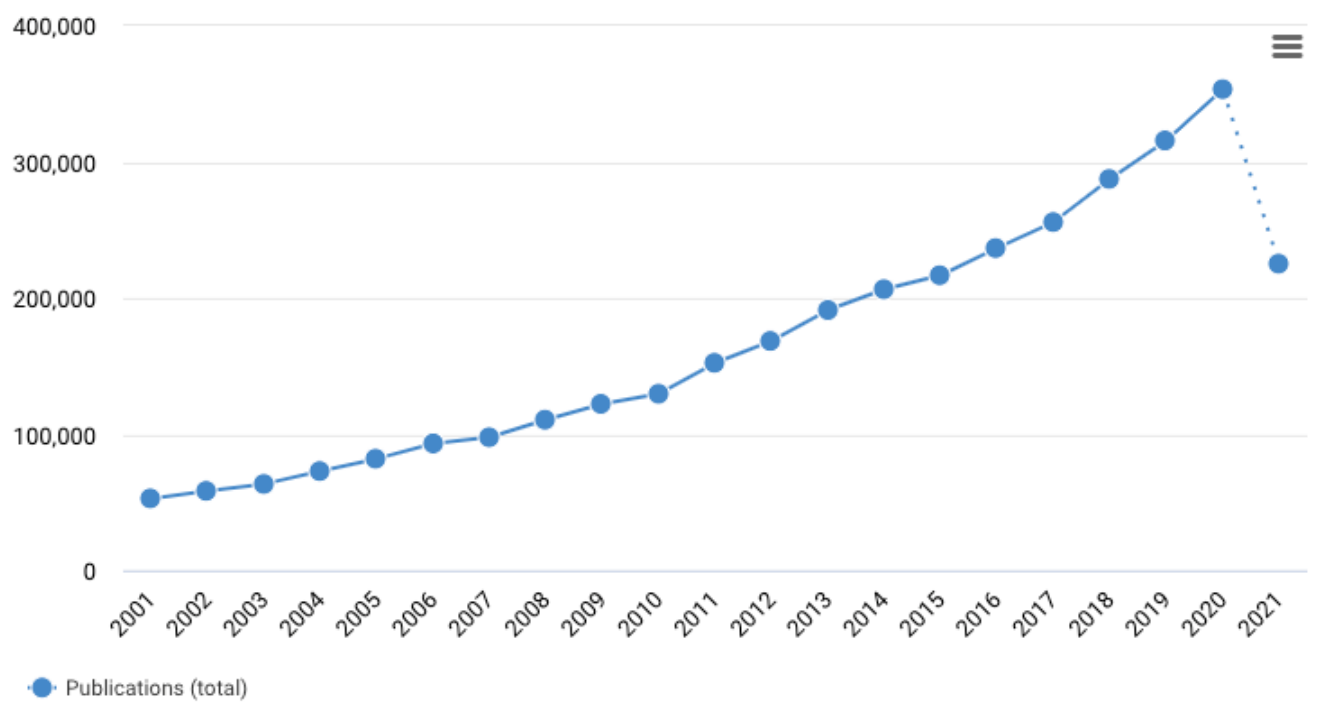

Figure 2. Publications of simulation research from 2001 to 2021 (sourced from the author's analysis on Dimensions)

The engineering field dominates in the field of science using this research method taking nearly $40 \%$ overall. In comparison, information and computing science is the second place with 368,372 articles. The distribution of simulation studies from 2001 to 2021 is represented in Figure 2. The numbers of articles are increasing over time; from only 50,000 articles in 2001, there are more than 400,000 simulation articles published in 2020. The year 2021 has more than 200,000 simulation research calculating up to now (July) because it has not ended yet. IEEE is the most popular simulated publisher with more than 20,742 articles. Still, the Journal of Geophysical Research is the most-cited journal related to simulation modeling works with a total of 798,394 times, as illustrated in Figure 3.

\begin{tabular}{|c|c|c|c|}
\hline Name & $\downarrow$ Publications & Citations & $\begin{array}{r}\text { Citations } \\
\text { mean }\end{array}$ \\
\hline IEEE Access & 20,742 & 149,916 & 7.23 \\
\hline PLOS ONE & 19,766 & 405,893 & 20.53 \\
\hline Journal of Physics Conference Series & 17,861 & 35,946 & 2.01 \\
\hline Applied Mechanics and Materials & 17,693 & 15,115 & 0.85 \\
\hline Scientific Reports & 16,343 & 276,735 & 16.93 \\
\hline Biophysical Journal & 15,404 & 248,413 & 16.13 \\
\hline Journal of Geophysical Research & 14,673 & 798,394 & 54.41 \\
\hline IOP Conference Series Materials Science and... & 14,379 & 16,595 & 1.15 \\
\hline Energies & 13,648 & 104,264 & 7.64 \\
\hline IFAC Proceedings Volumes & 12,327 & 49,259 & 4.00 \\
\hline
\end{tabular}

Figure 3. The top 10 journals for simulation research

Source: The author's analysis on Dimensions 


\subsection{The use of simulation models in business and management research}

As stated in The big book of simulation modeling, Borshchev (2013) confirms there are various well-known advantages of simulation modeling suitable for simulating business and organizational studies. However, comparing simulating studies in the business and management category of Dimensions with other disciplines, there are only 28,290 articles. The number of articles increased over time from 448 to more than 3,178 articles in 2020, as seen in Figure 4.

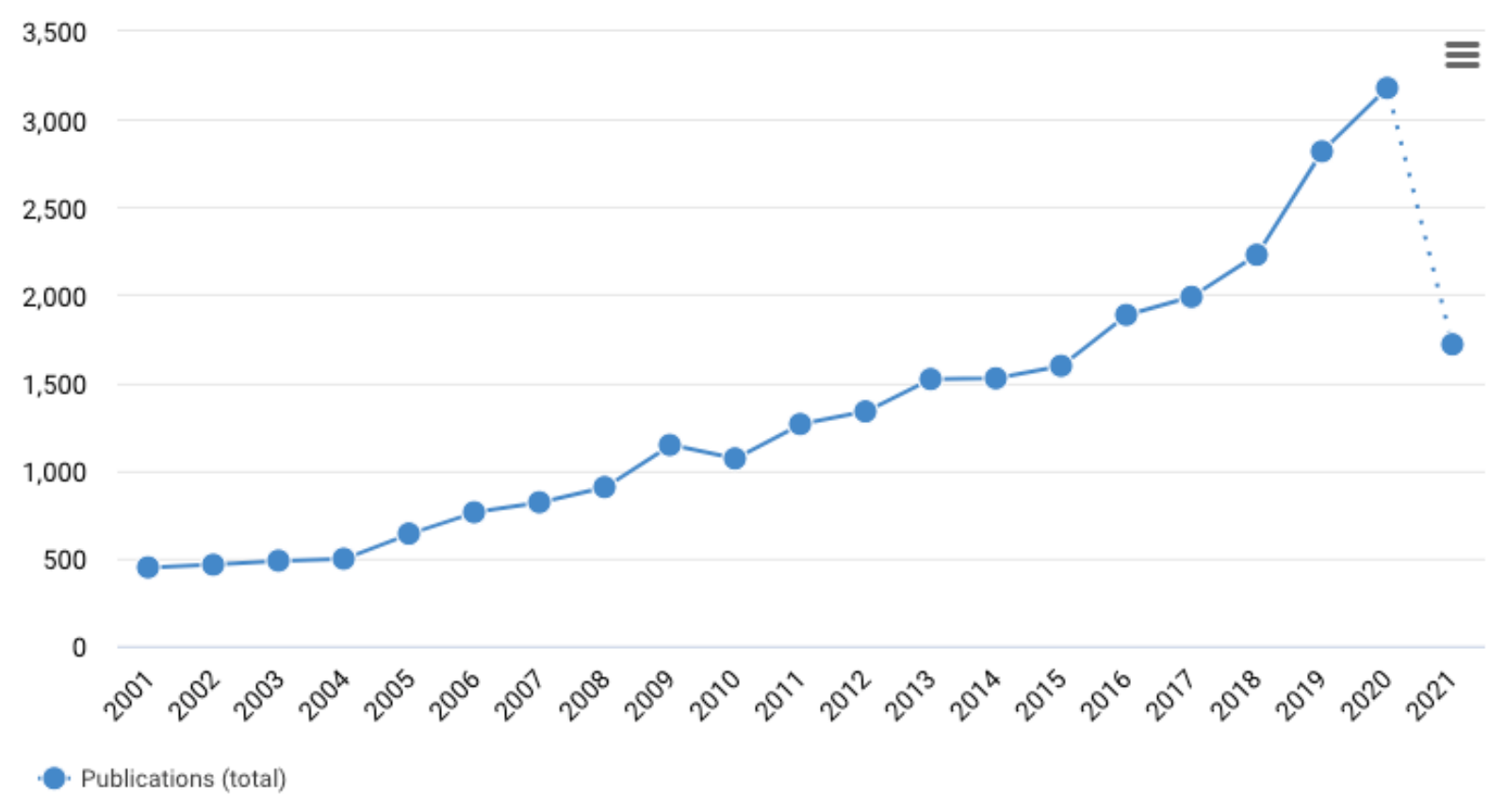

Figure 4. Published simulation works in business and management from 2001 to 2021

Source: The author's analysis on Dimensions

As seen in Figure 5, there are the top 20 journals publishing simulation modeling papers in the business and management discipline. They are top journals related to manufacturing, operation, supply chain, decision science, strategic management, marketing, risk analysis, and retailing. International Journal of Computer Integrated Manufacturing is the leading publisher of simulated papers. The highest impact journal is the Strategic Management Journal, with 28,726 citations within 21 years. Researchers contribute the most simulated works in this field are listed in Figure 6. They are from the United States, Germany, India, UK, Denmark, and France. Among the authors, Angappa Gunasekaran contributes the most in applying simulation modeling for the field of Supply chain management with 65 publications and has more than 6,000 citations. However, Marko Sarstedt is the most cited author in the list accounting for 14,881 citations with only 26 publications in the field of marketing. 


\begin{tabular}{|c|c|c|c|}
\hline Name & $\downarrow$ Publications & Citations & $\begin{array}{r}\text { Citations } \\
\text { mean }\end{array}$ \\
\hline International Journal of Computer Integrated ... & 673 & 9,003 & 13.38 \\
\hline International Journal of Simulation and Proce... & 660 & 1,595 & 2.42 \\
\hline International Journal of Production Research & 517 & 19,198 & 37.13 \\
\hline Production and Operations Management & 483 & 18,847 & 39.02 \\
\hline International Journal of Production Economics & 440 & 24,855 & 56.49 \\
\hline Omega & 371 & 16,449 & 44.34 \\
\hline System Dynamics Review & 333 & 9,011 & 27.06 \\
\hline Production Planning \& Control & 266 & 5,740 & 21.58 \\
\hline Decision Sciences & 236 & 10,467 & 44.35 \\
\hline Engineering Construction \& Architectural Ma... & 223 & 2,456 & 11.01 \\
\hline Strategic Management Journal & 221 & 28,726 & 129.98 \\
\hline International Journal of Quality \& Reliability ... & 219 & 3,624 & 16.55 \\
\hline European Journal of Operational Research & 203 & 9,746 & 48.01 \\
\hline Journal of Business Research & 201 & 7,991 & 39.76 \\
\hline Industrial Marketing Management & 201 & 7,597 & 37.80 \\
\hline International Journal of Operations \& Product... & 201 & 9,874 & 49.12 \\
\hline Journal of Management & 192 & 22,060 & 114.90 \\
\hline Risks & 192 & 628 & 3.27 \\
\hline Business Process Management Journal & 188 & 4,171 & 22.19 \\
\hline Journal of Retailing and Consumer Services & 186 & 4,972 & 26.73 \\
\hline
\end{tabular}

Figure 5. Top 20 journals in business and management related to simulation modeling Source: The author's analysis on Dimensions 


\begin{tabular}{|c|c|c|c|}
\hline $\begin{array}{l}\text { Name } \\
\text { Organization, Country }\end{array}$ & $\downarrow$ Publications & Citations & $\begin{array}{r}\text { Citations } \\
\text { mean }\end{array}$ \\
\hline $\begin{array}{l}\text { Angappa Gunasekaran } \\
\text { California State University, Bakersfield, Un }\end{array}$ & 65 & 6,087 & 93.65 \\
\hline $\begin{array}{l}\text { Dmitry Aleksandrovich Ivanov } \\
\text { Berlin School of Economics and Law, Gerr }\end{array}$ & 40 & 2,577 & 64.42 \\
\hline $\begin{array}{l}\text { Joseph Sarkis } \\
\text { Worcester Polytechnic Institute, United St }\end{array}$ & 37 & 2,172 & 58.70 \\
\hline $\begin{array}{l}\text { Ravi Shankar } \\
\text { Indian Institute of Technology Delhi, India }\end{array}$ & 30 & 424 & 14.13 \\
\hline $\begin{array}{l}\text { Denis R Towill } \\
\text { Cardiff University, United Kingdom }\end{array}$ & 30 & 1,837 & 61.23 \\
\hline $\begin{array}{l}\text { Kannan Govindan } \\
\text { University of Southern Denmark, Denmark }\end{array}$ & 29 & 1,590 & 54.83 \\
\hline $\begin{array}{l}\text { Rameshwar Dubey } \\
\text { Montpellier Business School, France }\end{array}$ & 28 & 1,815 & 64.82 \\
\hline $\begin{array}{l}\text { Jose Arturo Arturo Garza-Reyes } \\
\text { University of Derby, United Kingdom }\end{array}$ & 26 & 1,120 & 43.08 \\
\hline $\begin{array}{l}\text { Marko Sarstedt } \\
\text { Otto-von-Guericke University Magdeburg, }\end{array}$ & 26 & 14,881 & 572.35 \\
\hline Herman Aguinis & 25 & 2,728 & 109.12 \\
\hline
\end{tabular}

Figure 6. Top 10 researchers in business and management

Source: The author's analysis on Dimensions

In the discussion of the adoptions of simulation modeling, grounded on the works of Axelrod (1997) and Harrison et al. (2007), there are seven research purposes, including prediction, proof, discovery, explanation, critique, prescription, and empirical guidance. The author conducts preliminary research on these purposes using keyword strings search from seven research purposes in full data of Dimensions ["keyword" AND simulation modeling] from 2001 to 2020 to analyze how many articles relate in business and management category. The results show in Table 1.

\section{Table 1}

The numbers of simulated papers related to research purposes

\begin{tabular}{|c|c|c|c|}
\hline \multicolumn{1}{|c|}{ Keyword } & Publications & Citations & Citations mean \\
\hline Prediction & 8,236 & 264,000 & 32.02 \\
\hline Proof & 3,386 & 80,000 & 23.73 \\
\hline Discovery & 4,019 & 141,000 & 35.05 \\
\hline Explanation & 9,681 & 347,000 & 35.86 \\
\hline Critique & 2,621 & 110,000 & 42.05 \\
\hline Prescription & 1,544 & 63,000 & 40.69 \\
\hline Guidance & 5,438 & 185,000 & 33.98 \\
\hline
\end{tabular}

Source: The author's analysis on Dimensions 
Simulated research related to prediction and explanation takes over more than 17,000 publications, but critique papers have the highest citations mean. Please keep in mind that the search for research purposes only provides an overview of simulated studies. Many researchers have combined these research purposes that cannot be counted precisely. For example, the case of Guan et al. (2020) is published research on Nature Human Behaviour which is a very high-impact journal in the area of business and management. They use the multiple method simulation models to investigate the complexity of the global supply-chain effects of the Covid-19 control measure. This research has the purpose of discovering, predicting, and guiding countries in ruling social distance policies. They prove that supply-chain losses related to initial Covid-19 lockdowns are primarily dependent on the number of countries imposing restrictions and that losses are more sensitive to the duration of a lockdown than its strictness by 36 scenarios. There are many same cases, such as the works of Otto, Willner, Wenz, Frieler, and Levermann (2017); Singh, Kumar, Panchal, and Tiwari (2021); Sinha, Bagodi, and Dey (2020). Based on the previous research, the role of simulation modeling in business and management research is discussed and suggested in Figure 7. Harrison et al. (2007) focus on the link between complex problems and simulation modeling as a theory development process. Previous theory and empirical research inform theory development and model construction, then new theory and research, in turn, feedback into the process.

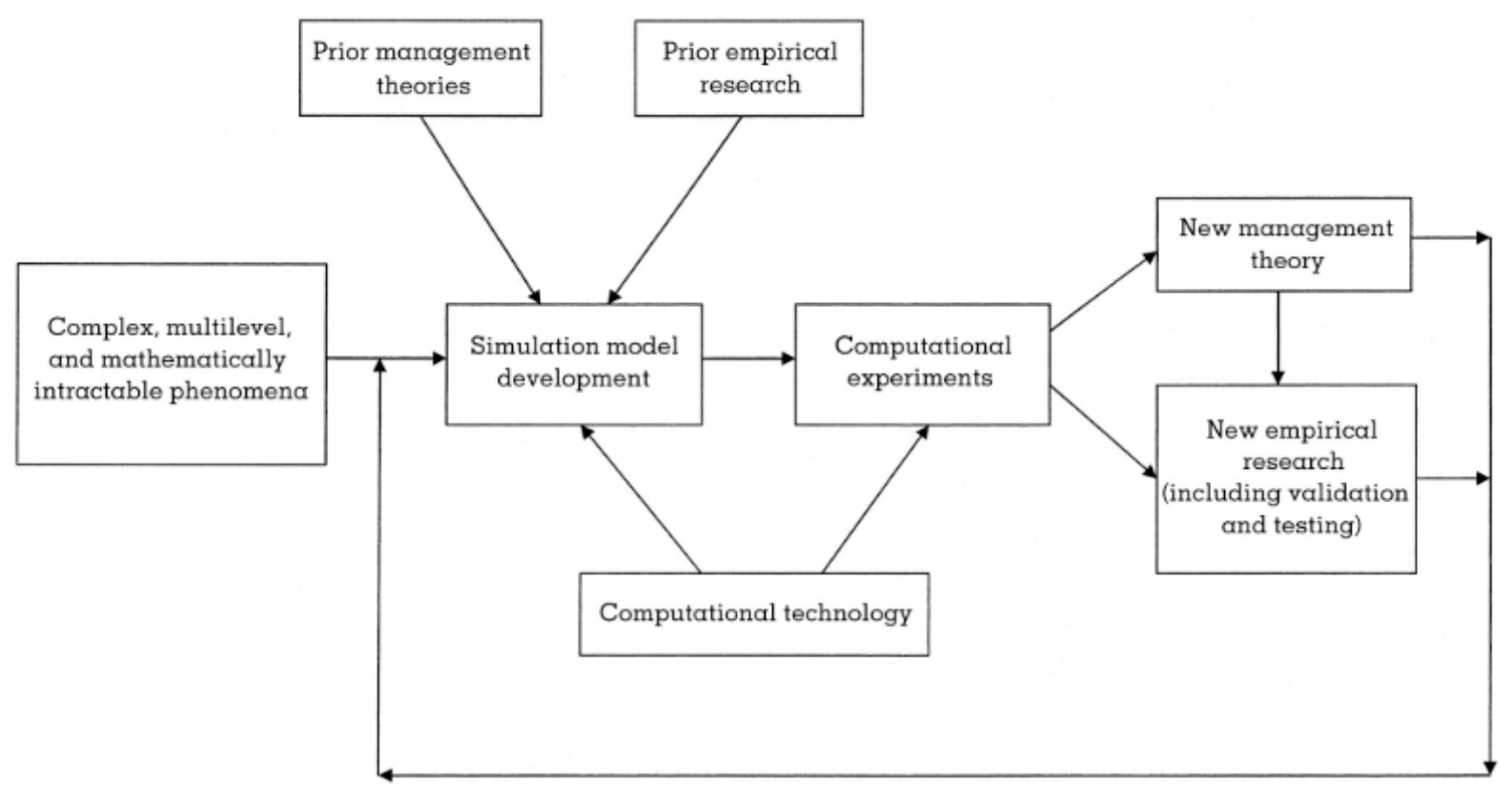

Figure 7. The interactive process of management theory and simulation modeling

Source: Harrison et al. (2007)

\section{Advantages and disadvantages of simulation methods}

\subsection{Advantages of simulation modeling}

First, the structure of the real system is naturally reflected by the construction of a simulation model (Borshchev, 2013). It is known that simulation models are developed mainly using visual languages. Thus, it is easier to communicate the model internals to other people. This reflection is usually based on researchers' observations and investigation, for example, deciding how best to build a shop model from the work of Borshchev (2013). A process flowchart where customers are entities and employees are resources in the model. An agent-based model, where 
consumers are agents affected by advertising, communication, and interaction with agentsemployees, are replicated. Also, there is a feedback structure, where sales are in the loop with advertising, quality of service, pricing, customer loyalty, and many related factors that exist in the shop. From this feature, simulation models enable modelers to analyze systems and find solutions where other methods (e.g., analytic calculations, linear programming) fail.

Second, the abstraction level of the corresponding models is a unique feature of some simulation applications. The models themselves are physical-level models where real-world objects are represented characteristically, such as physical interaction, dimensions, speeds, distances, timings, behaviors, decisions, and so on. Vasudevan and Devikar (2011) state that the abstraction level detail required in simulation determines the amount of information contained in the model. The quantity of information in a model decreases with the lowering levels of abstraction, which means that a low-level abstraction model contains more information than a high-level abstraction model. It is vital to model at the highest possible abstraction level to not compromise on the accuracy of outputs or ensuing decisions (Vasudevan \& Devikar, 2011). Therefore, it is noticed that modelers need to choose the right abstraction level, which is vital for the success of the modeling project. In the model development process, periodically reconsidering the abstraction level is recommended. Also, researchers can measure any value and track any object as long as it is not below the level of abstraction, which means measurements and statistical analysis are available at any time in a simulation model.

Third, developing a simulation model is a more straightforward process with the appropriate, and it typically requires less intellectual effort is scalable, incremental, and modular. Levinthal and Marengo (2016) argue simulation models can naturally accommodate more plausible behavioral assumptions on agents than utility (or profit) optimization than standard equilibrium models. Thus, the system behavior in time is playable and animable, known as one of the most significant advantages of simulation to illustrate the result, investigate interactions and debug assumptions in the model. 2D and 3D functions are prevalent and interesting for researchers to view and present their ideas lively when running most modeling software.

\subsection{Disadvantages of simulation modeling}

Though technology is the critical tool to implement and run the models, in some cases, it also constrains computational possibilities due to limitations on processing speed, storage, and programming features. This is the first limitation of simulation modeling. For example, agentbased modeling contains active objects (people, business units, animals, vehicles, projects, stocks, products, etc.) with timing, event order, and other individual behavior. For that kind of system, many tools can not develop agents efficiently and support complete migration from legacy stock and flow diagrams or process flowcharts to agents due to lack of a competency system.

The second limitation of simulation modeling lies in the level of model complexity. Usually, a simulation model is constructed by combining simplicity and elaboration (Harrison et al., 2007). Whenever introducing a simulation model, keep in mind that the most frequently raised question is "Why don't you add variables A, B, C to the model?" On the one hand, a model is more realistic by adding as many variables or processes as possible. On the other hand, it also becomes too challenging to understand what happens and drives the results in the model with a higher complicated level.

Finally, the value of simulation findings rests on the validity of the simulation model. In doing research, simulation modelers attempt to assess the model's behavior over a range of conditions under technically demanding and susceptible to errors in computer programming. Therefore, 
generated data by simulations do not entirely represent real observations and are limited by analysis techniques. These data must be interpreted with caution and further qualification when generalizing simulation findings to areas of the parameter space not examined in the simulation (Borshchev, 2013).

\section{Types of simulation models}

Considering the level of the model's abstraction and general framework for mapping a realworld system to its model, there are three main types of simulation models (Figure 8) introduced in this section. System dynamics are mainly used for strategic modeling at a high abstraction level, namely replicating queueing at a shop, a new product diffusion of a company. At medium and medium-low abstraction, discrete event modeling with the underlying process-centric approach is applied for a process to withdraw money in a bank, a job shop at a manufacturing company, or entrance admission process at a department of a university, etc. An agent-based model is more flexible in terms of abstraction; for instance, it can be very detailed where agents are modeling physical objects to highly abstract where agents are competing companies or governments (Borshchev, 2013). Also, there is the fourth type of simulation model, which combines the type mentioned above into the same model called the multiple method model is widely applied in many disciplines. These types of simulation modeling are discussed in the below subsections following their chronological order.

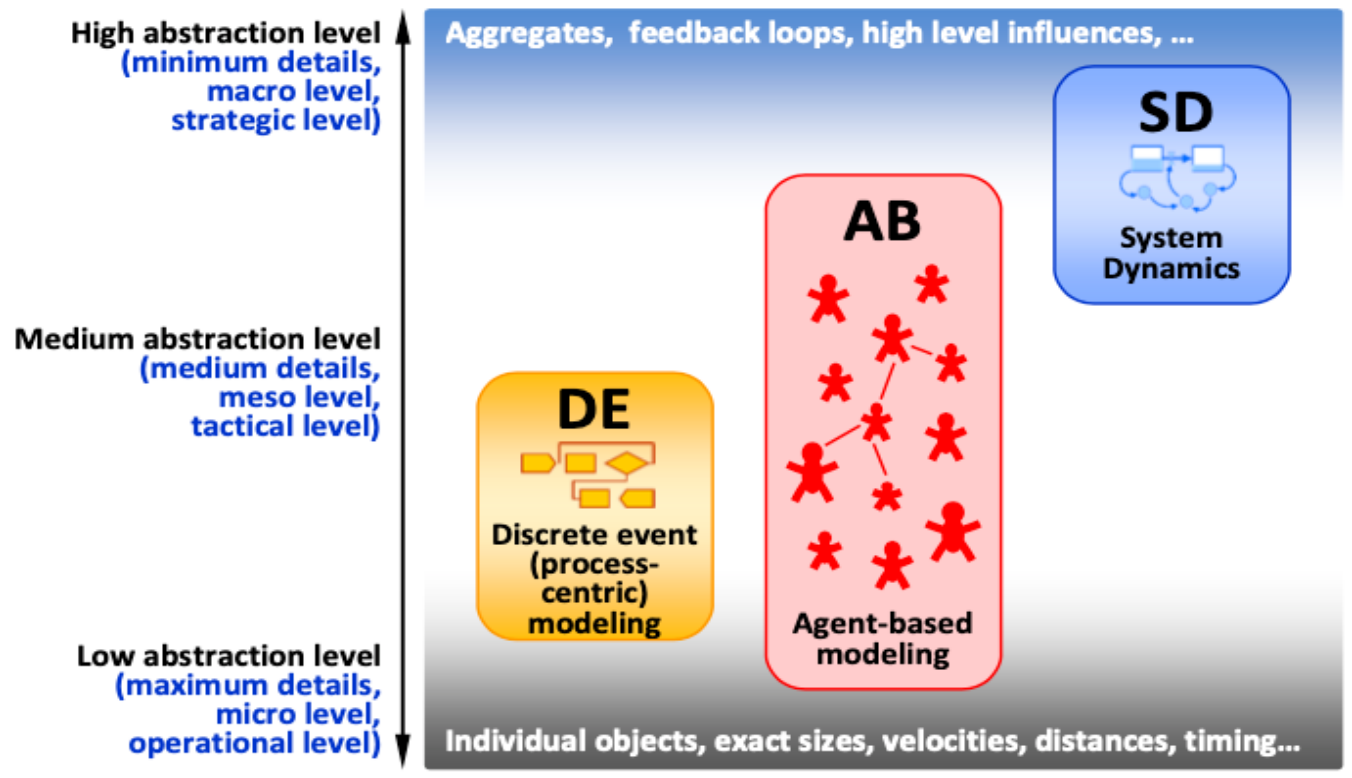

Figure 8. Three main types of simulation modeling

Source: Borshchev (2013)

\subsection{System dynamics}

System dynamics is a method created in the 1950s and early 1960s by MIT Professor Jay Wright Forrester whose original background was in science and engineering. He found the field of system dynamics, which examines complex business, economic, and environmental systems and the unexpected feedback that affects human activity created within them. System dynamics is a method of studying dynamic systems by taking an endogenous point of view. Modeling the system is considered as a causally closed structure that defines its behavior by itself. The feedback loops or circular causality are the heart of system dynamics, as seen in Figure 9, which is based on the Bass diffusion model applied for a product of Borshchev and Filippov (2004). It helps to 
identify stocks or accumulations that are potential adopters and adopters in the example model and the flows that affect them (Borshchev, 2013). Stocks are the memory of the system and sources of disequilibrium. In this method, individual events and decisions are considered as surface phenomena that ride on an underlying tide of system structure and behavior, which enables modelers to see things from a particular perspective of a continuous view where events and decisions are blurred (Sterman, 2000). In terms of mathematics, a system dynamics model consists of differential equations. There are two important characteristics of system dynamics modeling, according to Borshchev and Filippov (2004). First, the model works only with aggregates, which means the items in that same stock are indistinguishable; they do not have individuality. Second, the modeler has to provide global structural dependencies to quantify data for them accurately.

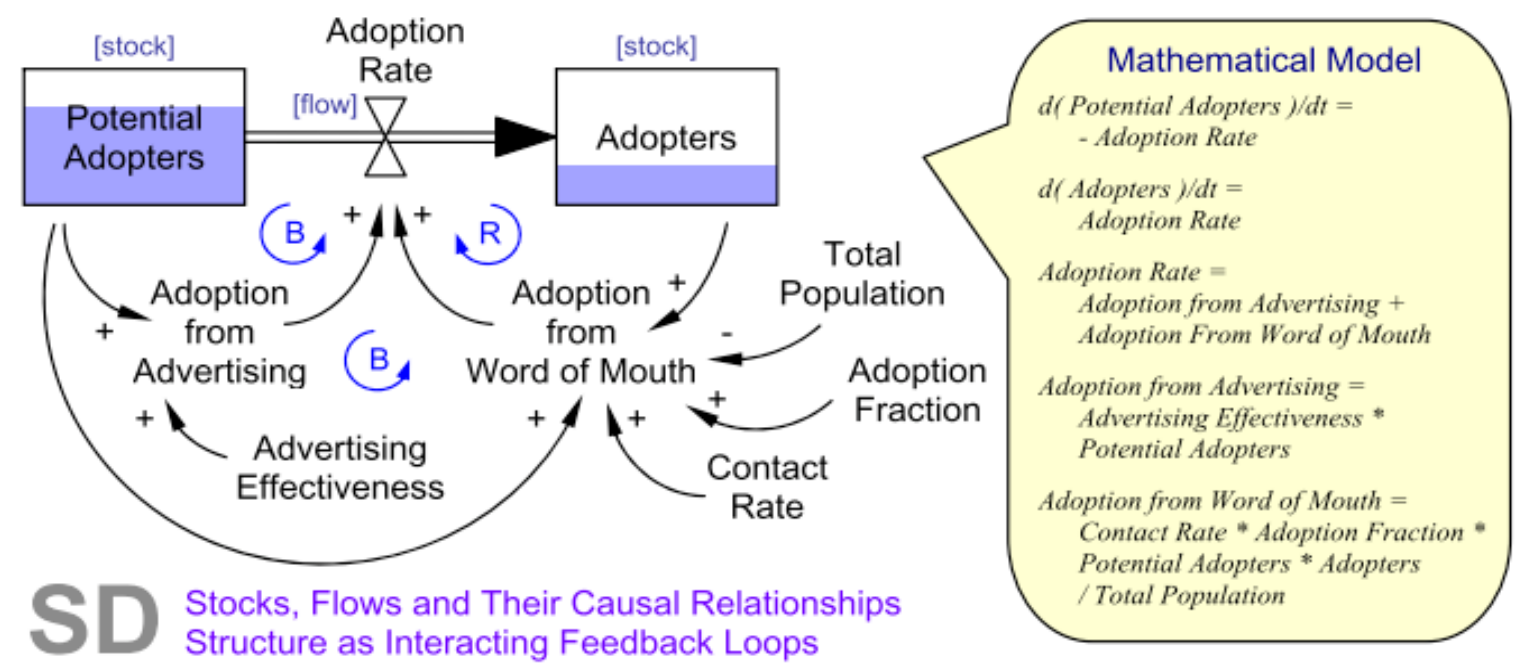

Figure 9. Example of a system dynamics in Vensim ${ }^{\mathrm{TM}}$

Source: Borshchev and Filippov (2004) and Sterman (2000)

\subsection{Discrete event modeling}

Discrete event modeling was introduced in October 1961 by IBM engineer Geoffrey Gordon as the first version of GPSS (Gordon's Programmable Simulation System), which is the first method of software implementation of discrete event modeling. The core of the discrete event modeling method is the system is modeled as a process which is a sequence of operations being performed across entities. A process commonly includes delays, usage of resources, and waiting in queues. In a discrete event model, each operation is specified graphically as a process flowchart containing the start event and end event, and no changes can take place in the model in between any two discrete events. The dynamics of the world are continuous due to no instant changes and no atomic changes. Each change in the real world can be further divided into phases of the processes, see Figure 10.

For instance, a company recruits new salespeople following the five-step selection process of Jobber and Lancaster (2017), including (1) preparation of job description, (2) identification of recruitment resource, (3) preparation of a shortlist, (4) interview, and (5) usage of supplementary selection aids. Depending on the level of abstraction and purpose of the model, monetary or number of employee usage of each step can be used in this model as instant events. Their component details may be irrelevant because only important moments in the system's lifetime are considered and treated as instantaneous and atomic events and abstracted away from anything that goes on between two contiguous events in discrete event modeling (Borshchev, 2013). 


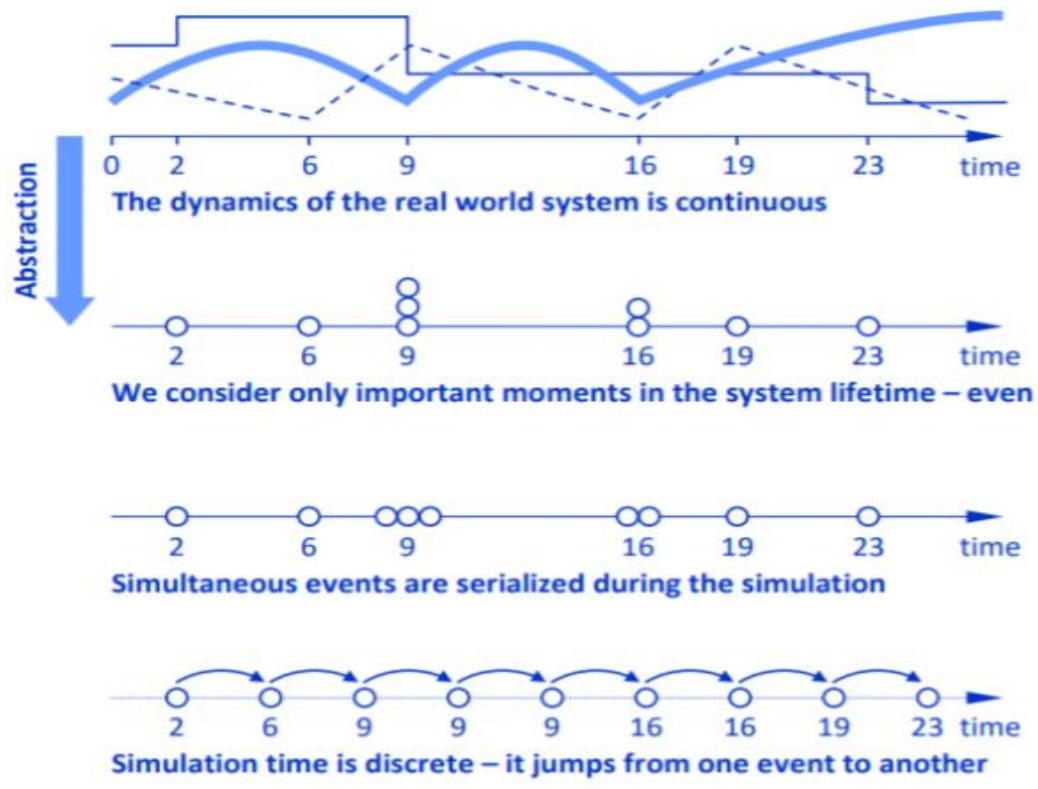

Figure 10. Discrete event in modeling

Source: Borshchev (2013)

\subsection{Agent-based modeling}

Established in 2002 - 2003, agent-based modeling is used to model the behaviors of adaptive actors who make up a social system and influence one another through their interactions (Harrison et al., 2007). It is created to get a deeper insight into systems that are not well-captured by traditional modeling approaches such as system dynamics and discrete events.

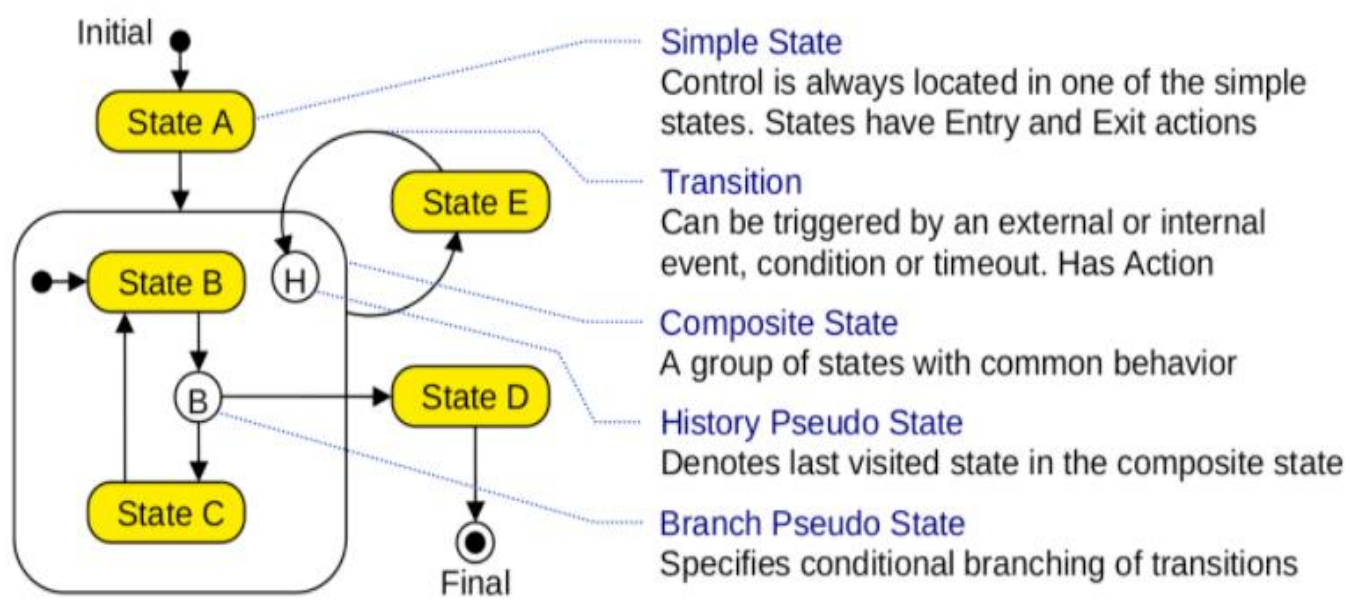

Figure 11. A typical statechart

Source: Borshchev and Filippov (2004)

This method is established thanks to advances in modeling technology coming from computer science and the rapid growth of the availability of CPU power and memory due to extensive usage of graphical editors or scripts to illustrate the divergent behavior of agents. In an agent-based model, the agent usually has a notion of state, and its actions and reactions depend on its state, whose behavior is specified with state charts (see Figure 11). The behavior of agents is defined in the form of rules executed upon special events (Borshchev \& Filippov, 2004). In some cases, the internal dynamics of the agent can be captured by system dynamics or discrete event approaches. 


\section{State-of-art simulation software}

The previous sections have presented the advantages of simulation modeling in business and management research and types of simulation modeling. In this section, there are several useful software for simulation modeling listed and compared their functions to make recommendations for researchers with regard to choosing the right tool. To do comparative research, there are many criteria involved to take advantage of technology. In this paper, the author focuses on criteria that are necessary for business and management research, including pricing, available features, cost, deployment, and best for (or the number of users) as well as the popular level of software and rating from users dividing research process into two rounds.

The first round is conducted based on the website Capterra.com which is used to create a suitable software shortlist for modeling in business and management containing at least three introduced models in this paper. There is 15 software including HSC Chemistry, ProcessModel, ExtendSim CP, Simcad Pro, Simio, FlexSim, PaleBlue, AnyLogic, Simul8, AutoTurn, Arena, Hash, Haulsim, Simile, Simulation Modeling. The second round proceeds based on the popular level of each software, including the number of users reviews and ratings on this website to compare only the four most used software. The result is summarized in Table 2.

\section{Table 2}

Comparison four most used and top rating simulation software

\begin{tabular}{|c|c|c|c|c|c|}
\hline & Features & AnyLogic & Simul8 & FlexSim & Simio \\
\hline \multirow{3}{*}{ Pricing } & Free trial & $X$ & $X$ & $\mathrm{X}$ & $X$ \\
\hline & Free education version & $\mathrm{X}$ & & $\mathrm{X}$ & $X$ \\
\hline & Starting from & & $\begin{array}{c}\$ 1995 \\
\text { One- } \\
\text { time/user }\end{array}$ & & \\
\hline \multirow{15}{*}{ Features } & Total features & $12 / 14$ & $10 / 14$ & $13 / 14$ & $11 / 14$ \\
\hline & 3D Modeling & $\mathrm{X}$ & & $\mathrm{X}$ & $\mathrm{X}$ \\
\hline & Agent-Based Modeling & $X$ & $\mathrm{X}$ & $\mathrm{X}$ & $\mathrm{X}$ \\
\hline & Continuous Modeling & $X$ & $X$ & $X$ & $X$ \\
\hline & Design Analysis & $\mathrm{X}$ & & $\mathrm{X}$ & $\mathrm{X}$ \\
\hline & Direct Manipulation & $\mathrm{X}$ & $\mathrm{X}$ & $\mathrm{X}$ & $\mathrm{X}$ \\
\hline & Discrete Event Modeling & $\mathrm{X}$ & $\mathrm{X}$ & $\mathrm{X}$ & $X$ \\
\hline & Dynamic Modeling & $X$ & $X$ & $\mathrm{X}$ & $\mathrm{X}$ \\
\hline & Graphical Data Presentation & $X$ & $X$ & $X$ & $X$ \\
\hline & Industry Specific Database & & & $\mathrm{X}$ & $\mathrm{X}$ \\
\hline & Monte Carlo Simulation & $\mathrm{X}$ & $\mathrm{X}$ & $\mathrm{X}$ & $X$ \\
\hline & Motion Modeling & $X$ & & $\mathrm{X}$ & \\
\hline & Presentation Tools & $\mathrm{X}$ & $X$ & $\mathrm{X}$ & $X$ \\
\hline & Stochastic Modeling & $X$ & $X$ & $X$ & \\
\hline & Turbulence Modeling & & & & \\
\hline Reviews & Overall & $\begin{array}{l}4.5 / 5 \text { stars } \\
265 \text { rating }\end{array}$ & $\begin{array}{c}4.5 / 5 \\
56\end{array}$ & $\begin{array}{c}4.6 / 5 \\
118\end{array}$ & $\begin{array}{c}4.7 / 5 \\
103\end{array}$ \\
\hline
\end{tabular}




\begin{tabular}{|c|c|c|c|c|c|}
\hline & Features & AnyLogic & Simul8 & FlexSim & Simio \\
\hline & Ease of Use & 3.9 & 4.3 & 4.1 & 4.2 \\
\hline & Customer Service & 4.2 & 4.8 & 4.6 & 4.6 \\
\hline & Features & 4.5 & 4.4 & 4.6 & 4.6 \\
\hline & Value for Money & 4.1 & 4.7 & 4.4 & 4.5 \\
\hline & Likelihood to recommend & $79.3 \%$ & $87.5 \%$ & $87.8 \%$ & $89.6 \%$ \\
\hline & Cloud, SaaS, Web-based & $X$ & $X$ & $\mathrm{X}$ & $X$ \\
\hline Donloyment & Windows & $\mathrm{X}$ & $\mathrm{X}$ & $\mathrm{X}$ & $\mathrm{X}$ \\
\hline weproyment & Mac & $\mathrm{X}$ & & & \\
\hline & Linux & $\mathrm{X}$ & & & \\
\hline & $1-50$ users & & & & \\
\hline Best for & 1-1000+ users & $\mathrm{X}$ & & $\mathrm{X}$ & $\mathrm{X}$ \\
\hline & From 1000 user & & $\mathrm{X}$ & & \\
\hline
\end{tabular}

Source: The researcher's data analysis

In summary, each software has pros and cons. FlexSim is the top feature software with 13/14 features in comparison, and Simio receives the highest rating and has an industry-specific database. Simul8 could use for more than 1,000 users, which is suitable for large collaborative works within an organization. AnyLogic is the most popular software with 265 rating times from its users with 4.5 over 05 stars along with 12/14 features and a free version for personal learning purposes. Most of the software support cloud-based environment and popular operating systems such as Windows; only AnyLogic supports Mac and Linux. Also, there are a lot of instructions and user guidelines from AnyLogic to support the new users in modeling and troubleshooting problems. Regarding research activities within universities, AnyLogic might be handy for researchers with a free version containing many features and friendly functions to do simulation modeling.

\section{Conclusions}

This paper has introduced simulation modeling as an effective method considering its contribution, strengths and weakness, flexible types of models, and effective software for specific research problems in business and management studies based on comparative analysis and Dimensions databases. The most apparent purpose of this study is a calling for more simulationbased work in the field of business and management. Usually, it is not easy to tackle study problems with other scientific approaches, but we are supported by advanced technology, and a simulation is a powerful tool for science.

In general, it seems that in business and management, organizations are complicated systems, and many of their characteristics and behaviors are often inaccessible and timeconsuming to researchers. Simulation is instrumental in developing theory and guiding empirical work (Harrison et al., 2007). The operation of complex systems can be simplified and easier to be deeply explored their behaviors. However, the major limitation of simulation research, just like any other research method, rests on the validity of the simulation model. It frequently must be constructed with little guidance by previous works or published papers in the same research area. Therefore, it can be prone to misspecification and misinterpretation by researchers.

This study is limited by the existing literature about the usefulness and popular types of simulation modeling in business and management discipline. It is noticed that simulation is not 
very popular in business and management knowledge compared to other fields. Considerably more work will need to be done to explore and apply the introduced simulation models as a legitimate, disciplined, and powerful approach that can make significant contributions to business and management theory. As a result, later models will be more concreted based on previously established works. Otherwise, the validity of simulation research can not be improved in this discipline.

This study also informs that there is various available software for business and management researchers. Each software has its pros and cons regarding cost, features, deployment, and situation. The comparison among software could support new simulation users in selecting the appropriate one for each research purpose. Future works with the application of modeling and different software for the same situation could be interesting to compare and contrast their advantages and disadvantages to deal with the complexity of systems and methods in simulation-based research.

\section{References}

Adams, J., Draux, H., Jones, P., Osipov, I., Porter, S., \& Szomszor, M. (2018). Dimensions - A collaborative approach to enhancing research discovery. Retrieved July 21, 2021, from https://www.dimensions.ai/resources/a-collaborative-approach-to-enhancing-researchdiscovery/

Axelrod, R. (1997). The complexity of cooperation: Agent-based models of competition and collaboration. Princeton, NJ: Princeton University Press.

Bode, C., Herzog, C., Hook, D., \& Mcgrath, R. (2019). A collaborative approach to creating a modern infrastructure for data describing research: Where we are and where we want to take it. Retrieved July 22, 2021, from 10.6084/m9.figshare.5783094

Borshchev, A. (2013). The big book of simulation modeling - AnyLogic simulation software. Retrieved July 20, 2021, from Anylogic North America website: http://www.anylogic.com/big-book-of-simulation-modeling

Borshchev, A., \& Filippov, A. (2004). From system dynamics and discrete event to practical agent based modeling: Reasons, techniques, tools. International Conference of The System Dynamics Society, 22, 25-29.

Bresciani, S., Ciampi, F., Meli, F., \& Ferraris, A. (2021). Using big data for co-innovation processes: Mapping the field of data-driven innovation, proposing theoretical developments and providing a research agenda. International Journal of Information Management, 60, Article 102347. doi:10.1016/j.ijinfomgt.2021.102347

Creswell, J. W., \& Creswell, J. D. (2018). Research design: Qualitative, quantitative, and mixed methods approaches (5th ed.). Los Angeles, CA: SAGE.

Esser, F., \& Vliegenthart, R. (2017). Comparative research methods. In The international encyclopedia of communication research methods (pp. 1-22). Hoboken, NJ: Wiley.

Gnanapragasam, S. N., Hodson, A., Smith, L. E., Greenberg, N., Rubin, G. J., \& Wessely, S. (2021). COVID-19 survey burden for healthcare workers: Literature review and audit. Public Health. Advance online publication. doi:10.1016/j.puhe.2021.05.006

Guan, D., Wang, D., Hallegatte, S., Davis, S. J., Huo, J., Li, S., ... Gong, P. (2020). Global supplychain effects of COVID-19 control measures. Nature Human Behaviour, 4(6), 577-587. doi:10.1038/s41562-020-0896-8 
Hantrais, L. (2008). International comparative research: Theory, methods and practice. London, UK: Macmillan International Higher Education.

Harrison, J. R., Lin, Z., Carroll, G. R., \& Carley, K. M. (2007). Simulation modeling in organizational and management research. Academy of Management Review, 32(4), 12291245. doi:10.5465/amr.2007.26586485

Hook, D. W., Porter, S. J., \& Herzog, C. (2018). Dimensions: Building context for search and evaluation. Frontiers in Research Metrics and Analytics, 3, 1-11. doi:10.3389/frma.2018.00023

Jiang, Y., \& Wen, J. (2020). Effects of COVID-19 on hotel marketing and management: A perspective article. International Journal of Contemporary Hospitality Management, 32(8), 2563-2573. doi:10.1108/IJCHM-03-2020-0237

Jobber, D., \& Lancaster, G. (2017). Selling and sales management (8th ed.). London, UK: Pearson Education, Inc.

Levinthal, D. A., \& Marengo, L. (2016). Simulation modelling and business strategy research. In M. Augier \& D. J. Teece (Eds.), The palgrave encyclopedia of strategic management (pp. 1-5). London, UK: Palgrave Macmillan.

Maina, J., \& Mwangangi, P. (2020). A critical review of simulation applications in supply chain management. Journal of Logistics Management, 2020(1), 1-6. doi:10.5923/j.logistics.20200901.01

Mills, M., van de Bunt, G. G., \& de Bruijn, J. (2006). Comparative research. International Sociology, 21(5), 619-631. doi:10.1177/0268580906067833

Otto, C., Willner, S. N., Wenz, L., Frieler, K., \& Levermann, A. (2017). Modeling losspropagation in the global supply network: The dynamic agent-based model acclimate. Journal of Economic Dynamics and Control, 83, 232-269. doi:10.1016/j.jedc.2017.08.001

Singh, S., Kumar, R., Panchal, R., Manoj, \& Tiwari, M. K. (2021). Impact of COVID-19 on logistics systems and disruptions in food supply chain. International Journal of Production Research, 59(7), 1993-2008. doi:10.1080/00207543.2020.1792000

Sinha, D., Bagodi, V., \& Dey, D. (2020). The supply chain disruption framework post COVID19: A system dynamics model. Foreign Trade Review, 55(4), 511-534. doi:10.1177/0015732520947904

Sterman, J. D. (2000). System dynamics: Systems thinking and modeling for a complex world. Cambridge, MA: Massachusetts Institute of Technology.

Thierry, C., Bel, G., \& Thomas, A. (2010). The role of modeling and simulation in supply chain management. SCS M\&S Magazine, 1(2010), 1-8.

Vasudevan, K., \& Devikar, A. (2011). Selecting simualtion abstraction levels in simulation models of complex manufacturing systems. Proceedings of the 2011 Winter Simulation Conference (WSC), 66, 2268-2277. doi:10.1109/WSC.2011.6147938

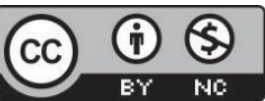

Creative Commons Attribution-NonCommercial 4.0 International License. 